\section{§3. Compatibility of Low Activation Ferritic Steels with Liquid Lithium}

Xu, Q. (Grad. Univ. Advanced Studies), Kondo, M., Muroga, $\mathrm{T}$.

One of the primary requirements for the development of fusion as an energy source is the qualification of materials for the first-wall/blanket system that will provide high performance and exhibit favorable safety and environmental features. Both economic competitiveness and the environmental attractiveness of fusion will be strongly influenced by the materials constraints. A key aspect is the development of a compatible combination of materials for the various functions of structure.

The compatibility of Reduced Activation Ferrite/Martensite steels (RAFM) with Liquid Lithium (Li) was investigated before. The main concerned of RAFM in the liquid $\mathrm{Li}$ environment was summarized as weight loss and the depletion of carbon, which led to the phase transformation from martensite to ferrite. The phase change resulted in an obvious reduction of hardness on the specimen surface. The investigation was carried out to explore the mechanism of phase transformation and decarburization in current work.

JLF-1(Fe-9Cr-2W) coupon specimens with the size of $26 \times 5 \times 0.25 \mathrm{~mm}$ were cut from sheet. The coupon specimens were exposed in liquid $\mathrm{Li}$ in different containers which were made by Mo, SS316 and $\mathrm{Nb}$ for 250 hours at $600^{\circ} \mathrm{C}$. After the experiment, weight loss measurement, chemical analysis and the SEM/EDS observation were carried out to investigate the corrosion characteristic in different containers.

After static Li exposure, the specimens exposed in Mo and $\mathrm{Nb}$ crucible lost weight, while the specimens gained weight in SS316 crucible, due to the Ni precipitation from crucible materials. There was no phase change was found on cross section after exposure in the Ni crucible, on the other side the phase transformation from martensite to ferrite occurred on the specimens exposed in the Mo crucible and $\mathrm{Nb}$ crucible. The depth of phase change was around $10 \mu \mathrm{m}$ and $20 \mu \mathrm{m}$ respectively. According to Gibbs free energy, it seems that the Mo and $\mathrm{Nb}$ acted as C-trap and caused the decarburization and phase change during exposure in liquid Li. Because of high affinity of $\mathrm{Nb}$ with $\mathrm{C}$, the deepest phase change was observed on specimen exposed in $\mathrm{Nb}$ container. The Mo-Fe-Cr particle was found on the surface of specimens and the Mo holder after experiment. The formation of Mo particle indicated that the interaction between JLF-1, Li and container materials took place during $\mathrm{Li}$ attack.
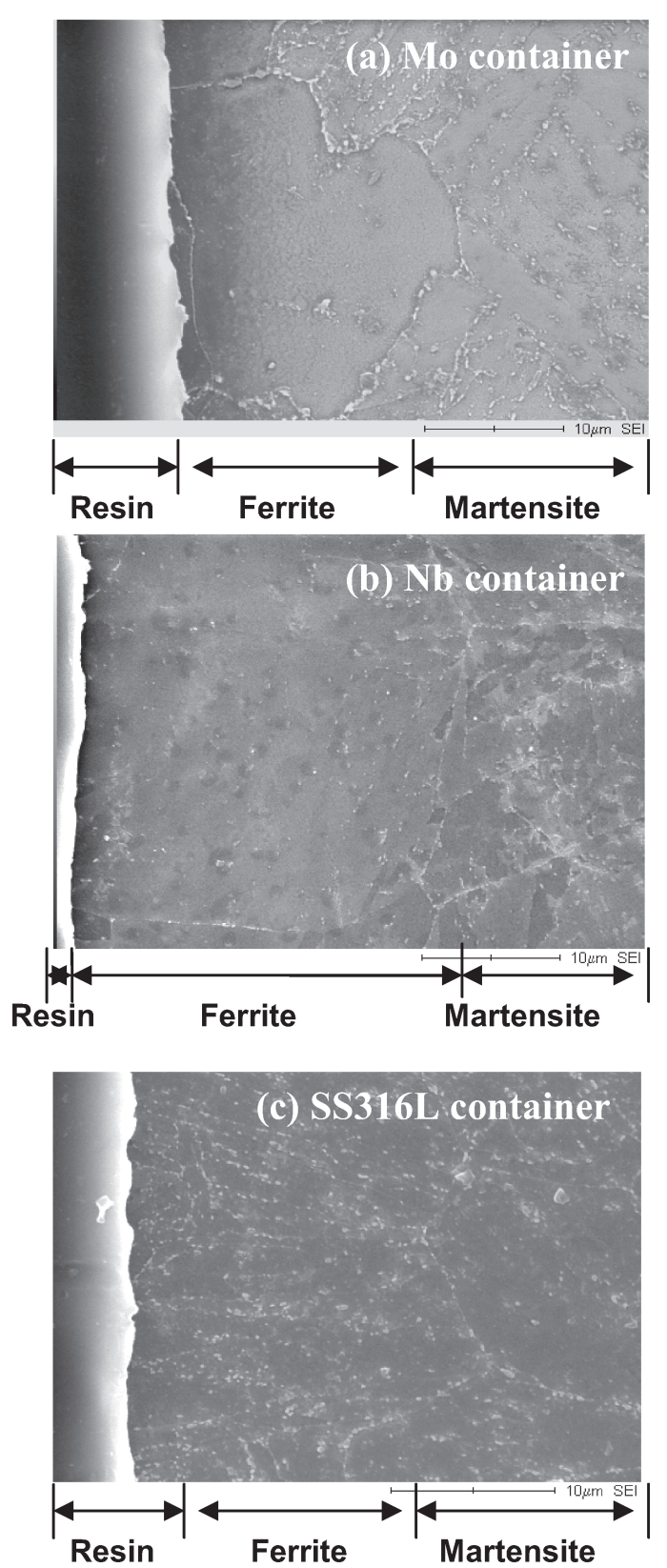

Fig.1 Cross section of JLf-1 specimens after exposure in Li in (a) Mo container (b) Nb container (c) SUS316L container 